\title{
Apresentação
}

\section{Simpósio Internacional de Cultura e Comunicação na América Latina}

O IV Simpósio Internacional de Cultura e Comunicação na América Latina "Pensamento crítico latino-americano em debate: construção do conhecimento, investigações participativas e epistemologias decoloniais" foi realizado na Escola de Comunicações e Artes da USP entre os dias 12 e 15 de novembro de 2018. Esse evento foi realizado com a contribuição e auxílio de diversas instituições e pessoas. Dentre as instituições, a FAPESP (Fundação de Amparo a pesquisa no Estado de São Paulo), o PROLAM - Programa de PósGraduação da América Latina, a UNIVAP Universidade do Vale do Paraíba, especialmente o PLUR - programa de planejamento urbano, a Universidade de São Paulo, a Escola de Comunicações e Artes e o NAP Núcleo de Apoio a Pesquisa CELACC Centro de Estudos Latino Americanos sobre Cultura e Comunicação. Essas instituições cederam o espaço físico, pessoal, materiais de divulgação, kits e auxílio para traslado e permanência de pesquisadores da Colômbia, Buenos Aires e Canadá, além disso, pesquisadores e bolsistas do NAP CELACC trabalharam arduamente na organização do evento. Justamente pelo fato de o simpósio ter sido o resultado de um esforço coletivo, através do auxílio e ajuda de uma rede de pesquisadores e instituições, a importância dessa publicação ganha ainda mais significado, diante da crescente perda de incentivos a educação no Brasil. Grande parte dos trabalhos publicados nessa edição especial da Extraprensa foi resultante do esforço desses pesquisadores, que apesar da falta de recursos e apoios, mantiveram seus estudos e seu interesse em contribuir com a pesquisa sobre as temáticas comunicacionais da América Latina. Durante o evento, além das sete mesas de debate, foram apresentados cerca de 80 (oitenta) trabalhos científicos, que foram analisados e discutidos por professores da USP, Unicamp, Universidad Minuto de Dios (Colômbia), Univap, entre outras. Todos esses docentes e pesquisadores contribuíram com seus estudos para a compreensão da América Latina, espaço de tamanha complexidade, que não pode ser definido apenas pela sua territorialidade. Desse modo, apesar do trabalho de Sísifo da pesquisa brasileira, esse evento foi uma prova da força de vontade e sede de pesquisa que habita muitos dos acadêmicos da América Latina. Com temáticas diversas que perpassaram as áreas da gestão cultural, territorialidades, metodologias participativas, conflitos urbanos e comunicação, os trabalhos do IV SICCAL apontaram problemáticas e soluções para a nossa realidade. Essa farta produção, que será apresentada nesse número especial, nos apresenta uma outra direção, cuja bússola aponta firmemente para o Sul.

Me. Maíra Carvalho de Moraes Coordenadora Executiva IV SICCAL 